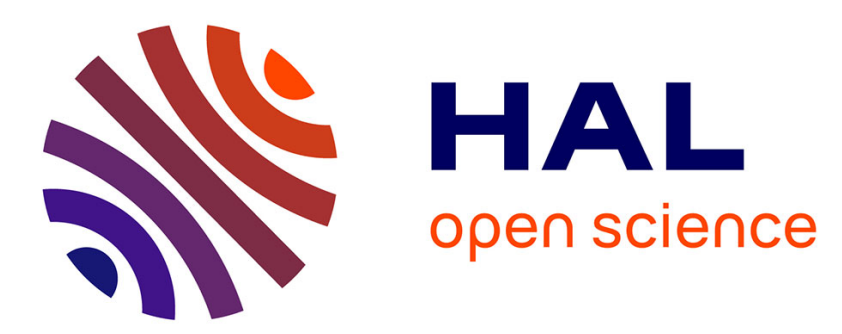

\title{
Growth and Properties of Multilayered Ba- and Sr-Ferrites' Films
}

\author{
T. Fujii, H. Kato, Y. Miura, J. Takada
}

\section{To cite this version:}

T. Fujii, H. Kato, Y. Miura, J. Takada. Growth and Properties of Multilayered Ba- and Sr-Ferrites' Films. Journal de Physique IV Proceedings, 1997, 07 (C1), pp.C1-485-C1-486. 10.1051/jp4:19971197 . jpa-00254847

\section{HAL Id: jpa-00254847 https://hal.science/jpa-00254847}

Submitted on 1 Jan 1997

HAL is a multi-disciplinary open access archive for the deposit and dissemination of scientific research documents, whether they are published or not. The documents may come from teaching and research institutions in France or abroad, or from public or private research centers.
L'archive ouverte pluridisciplinaire HAL, est destinée au dépôt et à la diffusion de documents scientifiques de niveau recherche, publiés ou non, émanant des établissements d'enseignement et de recherche français ou étrangers, des laboratoires publics ou privés. 


\title{
Growth and Properties of Multilayered Ba- and Sr-Ferrites' Films
}

\author{
T. Fujii, H. Kato, Y. Miura* and J. Takada \\ Department of Applied Chemistry, Okayama University, Tsushima-naka 3-1-1, Okayama 700, Japan \\ * Department of Environmental Chemistry and Materials, Okayama University, Tsushimanaka 1-1-1, \\ Okayama 700 Japan
}

\begin{abstract}
Thin films of c-axis oriented Ba- and Sr-hexaferrits (BaM and SrM) were prepared by reactive evaporation method without any post heat treatments. Subsequently growth of BaM/SrM multilayered films was tried and the sidebands in XRD clearly appeared. According to magnetization measurements all films had the perpendicular magnetic anisotropy. However the $\mathrm{M}_{\mathrm{s}}$ for BaM film was only $55 \%$ of that for the bulk. A broad background in Morssbauer spectrum for the BaM suggested the fluctuating magnetic moments. Though the $\mathrm{M}_{\mathrm{S}}$ for SrM film was improved it had some inplane magnetization components. To combine the advantages of BaM and SrM individual films, the BaM/SrM multilayered film exhibited good magnetic properties: The $\mathrm{M}_{\mathrm{S}}$ was recovered to about $80 \%$ of the bulk value and the inplane magnetization components disappeared in both the magnetization curves and the Mössbauer spectrum.
\end{abstract}

\section{INTRODUCTION}

Thin films of c-axis oriented Ba- and Sr-hexaferrites (BaM and SrM) are of great interest in their technological applications to magnetic recording and microwave devices [1]. Both have a magnetoplumbite structure with a large magnetocrystalline anisotropy along the c-axis. The anisotropy constants $\left(\mathrm{K}_{1}\right)$ of BaM and $\mathrm{SrM}$ for bulks are $3.3 \times 10^{5}$ and $3.6 \times 10^{5} \mathrm{~J} / \mathrm{m}^{3}$, and their saturation magnetizations $\left(\mathrm{M}_{\mathrm{S}}\right)$ are 380 and $365 \mathrm{G}$, respectively [2]. However magnetic properties of thin films are influenced by many factors like crystallinity, stoichiometry and strains of the films [3].

Reactive evaporation is a powerful technique to prepare well-crystallized and multilayered oxide films with controlled stoichiometry, by modifying the evaporation conditions such as evaporation sources, deposition rate and oxygen pressure. Since the lattice mismatch between BaM and SrM is only $0.4 \%$, well-crystallized but slightly strained BaM/SrM multilayered films are expected to form. We report here the structural and magnetic properties of c-axis oriented BaM, SrM and BaM/SrM multilayered films deposited on sapphire $\left(\alpha-\mathrm{Al}_{2} \mathrm{O}_{3}\right)$.

\section{EXPERIMENTAL}

$\mathrm{BaM} / \mathrm{SrM}$ films were prepared on $\alpha-\mathrm{Al}_{2} \mathrm{O}_{3}(0001)$ single-crystalline substrates by using reactive evaporation system. The system had three evaporation sources; two for Fe and Ba were heated by electron beams and one for Sr was by a crucible heater. After the chamber was evacuated to $2 \times 10^{-5}$ Torr, the substrate temperature was kept at $800^{\circ} \mathrm{C}$ and oxygen gas was introduced into the chamber to the pressure of $2 \times 10^{-4}$ Torr. Oxygen plasma was generated by if power supply of $200 \mathrm{~W}$. The ratio between $\mathrm{Ba}$ (or $\mathrm{Sr}$ ) and $\mathrm{Fe}$ deposition rate was controlled to 1:10 by quartz thickness monitors and the total deposition rate was fixed to about $1.0 \AA / \mathrm{s}$. These were the conditions that the growth of well-crystallized BaM and SrM films was confirmed in our system. Sample films were characterized by $\mathrm{x}$-ray diffraction (XRD) method with $\mathrm{Cu} \mathrm{K} \alpha$, magnetization measurement using a vibrating sample magnetometer (VSM), and conversion electron Mössbauer spectroscopy (CEMS). The thicknesses of the deposited films ranged up to $2000 \AA$.

\section{RESULTS AND DISCUSSION}

\subsection{BaM and SrM films}

XRD patterns for both BaM and SrM films clearly show the growth with good c-axis orientation on the substrate. However the pattern for BaM (Fig.l (a)) is a little broader than that for SrM (Fig.1(b)). According to the bulk phase diagrams of $\mathrm{BaO}_{-} \mathrm{Fe}_{2} \mathrm{O}_{3}$ and $\mathrm{SrO}-\mathrm{Fe}_{2} \mathrm{O}_{3}$ systems, liquid phase appears above $1315^{\circ} \mathrm{C}$ and $1195^{\circ} \mathrm{C}$, respectively [4]. Mobility of atoms on the substrate should influence the crystallinity of the films. During the deposition impinging atoms onto the substrate diffuse along the surface and subsequently condense into the crystal. Lower eutectic temperature for $\mathrm{SrO}-\mathrm{Fe}_{2} \mathrm{O}_{3}$ suggests the larger mobility of 
Sr than $\mathrm{Ba}$. Moreover the lattice mismatch between $\mathrm{SrM}$ and $\alpha-\mathrm{Al}_{2} \mathrm{O}_{3}$ is $7.0 \%$, while the one between $\mathrm{BaM}$ and $\alpha-\mathrm{Al}_{2} \mathrm{O}_{3}$ is $7.1 \%$. Thus the SrM film seems to have better crystallinity than the BaM film.

Magnetization curves of c-axis oriented BaM and SrM films measured by VSM indicate the perpendicular magnetic anisotropy as expected from the magnetocrystalline anisotropy of the bulks. However the $\mathrm{M}_{\mathrm{S}}$ of $210 \mathrm{G}$ for the BaM film is considerably smaller not only than that of the bulk, but also than that of $280 \mathrm{G}$ for the SrM film. Smaller Ms for BaM supports the XRD results of the poor crystallinity of the film. The easy axis coercivity of $\mathrm{H}_{C} \perp=2.7 \mathrm{kOe}$ for the SrM film is larger than that of $\mathrm{H}_{\mathrm{C}} \mathrm{L}=1.9 \mathrm{kOe}$ for the BaM film. While the hard axis coercivities of $\mathrm{H}_{\mathrm{d}} /$ for SrM and BaM are 1.9 and $0.1 \mathrm{kOe}$, respectively. The SrM film has some components with the inplane magnetization. If SrM has the negative magnetostriction constant $(\lambda \perp)$ as that for $\mathrm{BaM}$ [5], the inplane lattice contraction due to the lattice matching with $\alpha-\mathrm{Al}_{2} \mathrm{O}_{3}$ induces the inplane magnetic anisotropy.

A CEMS spectrum for the BaM film (Fig.2 (a)) is a typical Mössbauer pattern of BaM with small intensities in the second and fifth peaks of the sextets, though it is overlaid with a broad backgroud component. A broad background suggests the distributions in the magnetic hyperfine fields due to the poor crystallized region in the film. The small intensity ratio in the second and fifth peaks reflects the magnetization direction parallel to the $\gamma$-ray incidence, i.e. perpendicular magnetization axis against the film plane. While the spectrum for the SrM film (Fig.2 (b)) has a smooth backgroud with somewhat larger intensities in the second and fifth peaks. Though the film has the good crystallinity it has the inplane magnetic components parallel to the film plane. These are consistent with both the XRD and the magnetization measurements discussed above.

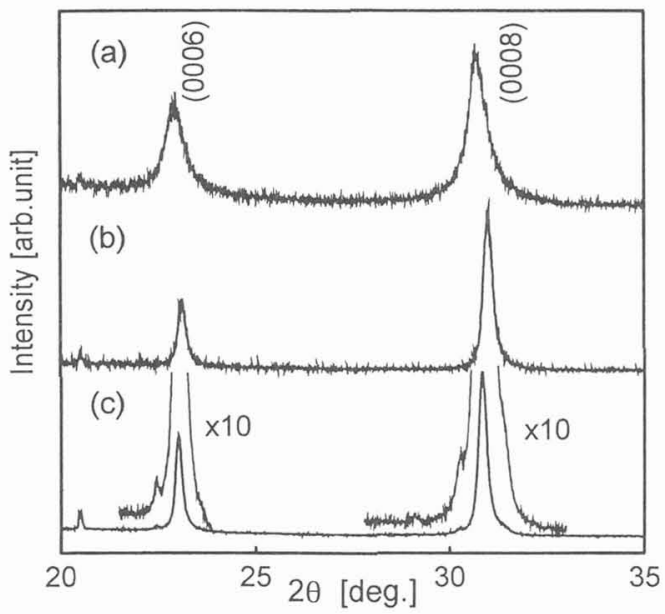

Figure 1: X-ray diffraction patterns for (a) BaM, (b) SrM, and (c) BaM/SrM multilayered films on $\alpha-\mathrm{Al}_{2} \mathrm{O}_{3}(0001)$.

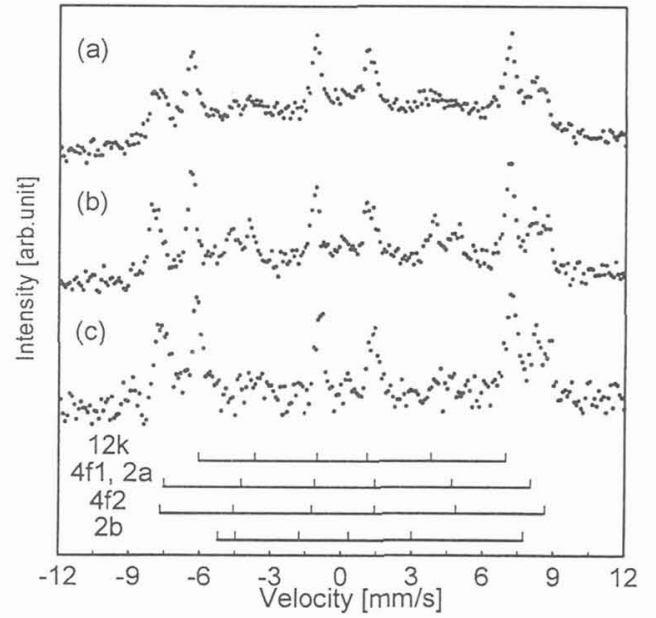

Figure 2: Room temperature Mössbauer spectra for (a) BaM, (b) $\mathrm{SrM}$, and (c) BaM/SrM multilayered films.

\subsection{BaM/SrM multilayered film}

Fig.1 (c) shows a typical XRD pattern for BaM/SrM multilayered films. The film was designed as $[\mathrm{BaM}(80 \AA) / \mathrm{SrM}(80 \AA)] 8$, consisting of $80 \AA$ of $\mathrm{BaM}$ and $80 \AA$ of $\mathrm{SrM}$ repeated 8 times. In spite of the high substrate temperature of $800^{\circ} \mathrm{C}$, small sidebands appears just beside the $(000 \mathrm{~L})$ lines when the individual BaM and SrM layers are thicker than $80 \AA$. A modulation period calculated from the sideband positions of this pattern is about $150 \AA$ which is nearly consistent with the designed value. The multilayered films clearly have the magnetic anisotropy perpendicular to the film plane, too. The $\mathrm{M}_{\mathrm{S}}$ of $290 \mathrm{G}$ is considerably improved than those of both BaM and SrM individual films. The measured $\mathrm{M}_{\mathrm{S}}$ is about $80 \%$ of the bulk value of $\mathrm{Ba}_{0.5} \mathrm{Sr}_{0.5} \mathrm{M}$. The easy axis coercivity is $\mathrm{H}_{\mathrm{C}} \mathrm{L}=2.5 \mathrm{kOe}$, while the hard axis coercivities is $\mathrm{H}_{\mathrm{C}} /=0.1 \mathrm{kOe}$. A typical CEMS spectrum for the multilayered films (Fig.2 (c)) shows a similar pattern to those for BaM and SrM films. Besides, the second and fifth peaks of the sextets almost vanish and the pattern has smooth background. The crystallinity and the perpendicular magnetic anisotropy are improved to form the multilayered BaM/SrM.

\section{Acknowledgments}

The authors are thankful to Prof. T. Shinjo (Kyoto Univ.) for his cooperation to the VSM measurements.

\section{References}

[1] T.L. Hylton, M.A. Parker, and J.K Howard, Appl. Phys. Lett. 61 (1992) 867.

[2] RS Tebble and D.J. Craik, Magnetic Materials (Wiley-Interscience, Londen, 1969).

[3] T. Fujii, M. Takano, R. Katano, Y. Isozumi, and Y. Bando, J. Magn. Magn. Mat. 135 (1994) 231.

[4] Y. Goto and T. Takada, J. Jpn. Soc. Powder and Powder Metal. 21 (1974) 21 (in Japanese).

[5] F. Licci and S. Rinaldi, J. Appl. Phys. 52 (1981) 2442. 